\title{
Autoconsumo e segurança alimentar: a agricultura familiar a partir dos saberes e práticas da alimentação ${ }^{1}$
}

\section{Self-consumption and food security: family agriculture based on eating knowledge and practices}

\author{
Renata MENASCHE \\ Flávia Charão MARQUES² \\ Cândida ZANETTI ${ }^{2}$
}

\section{R E S U M O}

\section{Objetivo}

Identificar e analisar as classificações e representações da alimentação, bem como as práticas de produção e consumo de alimentos entre agricultores e agricultoras da região do Vale do Taquari (Rio Grande do Sul, Brasil).

\section{Métodos}

Os dados e as informações foram obtidos a partir de entrevistas e observação participante, orientadas por um esquema metodológico qualitativo. Participaram da pesquisa, realizada em 2004 e 2005, 48 famílias rurais, de três diferentes localidades. Os recursos teórico-analíticos utilizados foram os da antropologia da alimentação e da abordagem da reciprocidade.

\section{Resultados}

Entre as famílias estudadas é significativa a produção de alimentos para autoconsumo, sendo as mulheres as principais responsáveis por sua obtenção. As práticas alimentares, embora tenham sofrido modificações, em

\footnotetext{
${ }^{1}$ Os resultados apresentados, breve e parcialmente neste artigo, compõem o livro "A agricultura familiar à mesa: saberes e práticas da alimentação no Vale do Taquari o projeto de pesquisa foi apoiado pelo Ministério da Ciência e Tecnologia, Ministério do Desenvolvimento Social e Combate à Fome e Conselho Nacional de Desenvolvimento Científico e Tecnológico, a partir do Edital MCT/MESA/CN Pq/CT-Agronegócio 01/2003 (processo CNPq no 503566/2003-9); a instituição executora foi a Fundação Estadual de Pesquisa Agropecuária, as instituições parceiras foram a Universidade Estadual do Rio Grande do Sul (UERGS) e o Programa de Pós-Graduação em Desenvolvimento Rural da Universidade Federal do Rio Grande do Sul.

A equipe multidisciplinar que conduziu a pesquisa, coordenada pela primeira autora deste artigo, foi composta pelos(as) pesquisadores(as): Flávia Charão Marques (PGDR/UFRGS), José Antônio Kroeff Schmitz (UERGS), Leonardo Beroldt (UERGS), Margarita Rosa Gaviria M ejia (PPGS/UFRGS) e Saionara Araujo Wagner (FEPAGRO); bem como pel os(as) então estudantes do Curso de Graduação em Desenvolvimento Rural e Gestão Agroindustrial da UERGS/Unidade de Encantado: Alex Genessini, Cândida Zanetti (IC/CN Pq), Cristiane Tonezer, Evander Eloí Krone, Everton Mundeleski, Ivan Cesar Tremarin, Karin Inês Lohmann Terhorst, Leila Claudete Schmitz (IC/CNPq) e Silvane Maria Pezzi.

2 Universidade Federal do Rio Grande do Sul, Programa de Pós-Graduação em Desenvolvimento Rural. Av. João Pessoa, 31, 90040-000, Porto Alegre, RS, Brasil. Correspondência para/Correspondence to: R. MENASCHE. E-mail: বrenata.menasche@pq.cnpq.br>.
} 
função da modernização da agricultura e da incorporação de produtos industrializados, guardam especificidades locais e estão relacionadas a diversas expressões de sociabilidade, como a circulação de alimentos e a realização de festas comunitárias, que, impregnadas por simbolismos, atualizam um modo de vida e têm garantido segurança alimentar.

\section{Conclusão}

As práticas de produção para autoconsumo das famílias estudadas estão associadas à sua segurança alimentar e, desse modo, às suas estratégias de reprodução social. A circulação de alimentos e as escolhas alimentares expressam relações de sociabilidade e de identidade nas comunidades rurais estudadas. Aspectos socioculturais e distintos níveis de relações sociais apresentam-se em transformação, podendo colocar em risco a segurança alimentar das famílias. Tais processos inspiram a realização novos estudos.

Termos de indexação: Antropologia cultural. Consumo de alimentos. Hábitos alimentares. Identidade de gênero. População rural. Segurança alimentar e nutricional.

\section{A B S T R A C T}

\section{Objective}

To identify and to analyze eating classifications and representations as well the food production and consumption practices among farmers from Vale do Taquari (Rio Grande do Sul, Brazil).

\section{Methods}

The data and information were collected from interviews and participatory observation, oriented by qualitative methods. The research involved 48 rural families from three different localities in 2004 and 2005. The theoretical and analytical resources were provided by food anthropology and reciprocity approach.

\section{Results}

The production of food for self-consumption among the studied families is significant and the main producers are women. Food practices have changed as a result of agricultural modernization and increased use of industrialized products, yet they maintain local specificity and are related to several expressions of sociability such as food exchanges and community parties. These are permeated by symbolisms that update the way of living and assure food security.

\section{Conclusion}

The production practices for autoconsumption of the studied families are associated with food security and, in this way, to social reproduction strategies. Food exchanges and food choices express relationships of sociability and identity in the studied rural communities. Social and cultural aspects and different levels of social relationships are undergoing a transformation which may jeopardize the food security of the families. Such processes are inspiring new studies.

Indexing terms: Anthropology, cultural. Food consumption. Food habits. Gender identity. Rural population. Food security.

\section{N T R O D U Ç Ã O}

Este artigo apresenta alguns dos resultados do projeto de pesquisa "A multifuncionalidade da agricultura à mesa: hábitos alimentares e produção para autoconsumo; identidade e estratégias de reprodução social de famílias rurais" ${ }^{1}$, levado a cabo na região do Vale do Taquari, Rio Grande do Sul, no período compreendido entre fevereiro de 2004 e fevereiro de 2006.
Nos últimos anos, inúmeros são os estudos que têm discutido as transformações pelas quais vem passando o rural brasileiro - a esse respeito, ver, por exemplo, os resultados de pesquisas do Projeto Rurbano ${ }^{2}$-, crescentemente percebido como mais que locus de realização da produção agrícola. Nessa perspectiva, cabe menção ao conjunto de iniciativas de pesquisa centradas no tema da multifuncionalidade ${ }^{3}$. A ocupação territorial e a manutenção do tecido social, assim como 
a preservação da paisagem, do meio ambiente e da diversidade cultural, são algumas das dimensões que vêm sendo apontadas enquanto constitutivas desse rural, em que se observam mudanças relacionadas, por exemplo, à promoção do turismo, do lazer, de locais alternativos de moradia, bem como à expansão de ocupaçõesnãoagrícolas. Considera-se que essas e outras mudanças em curso estão diretamente associadas a importantes transformações nas condições de vida e de trabalho daqueles que habitam o campo, que serão comentadas ao longo deste trabalho.

Foi ponto de partida para o desenvolvimento da pesquisa o entendimento de que 0 estudo das práticas alimentares das famílias rurais e das representações sociais a elas associadas constitui um caminho interessante para a apreensão de suas percepções a respeito da agricultura, da natureza e do rural, bem como do modo como suas vidas têm sido afetadas pelas recentes mudanças nele ocorridas.

Isso porque, ao mesmo tempo em que se sabe ser condição indispensável à sobrevivência dos seres humanos a satisfação de suas necessidades biológicas, entende-se que os indicadores nutricionais que a auferem são insuficientes quando se deseja apreender os significados da alimentação. Os alimentos não são apenas comidos, mas são também pensados ${ }^{4}$. $E$, desse modo, o ato alimentar implica em valoração simbólica. Ou, como dito por Fischler ${ }^{5}$, deve-se considerar que o homem é um onívoro que se alimenta de carne, de vegetais e de imaginário. Daí a diferenciação entre alimento (natureza) e comida (cultura), estabelecida por Da M atta ${ }^{6}$, ao analisar o caso brasileiro: " toda substância nutritiva é alimento, mas... nem todo alimento é comida" .

A fome e a sede são, então, formuladas e saciadas em termos culturais, sociais e históricos. O quê se come, com quem se come, quando, como e onde se come, as prescrições e proscrições alimentares são definidas pela cultura. É assim que as práticas, classificações e representações da alimentação indicam o status de um indivíduo em uma sociedade, bem como a cozinha de um grupo social, agindo na conformação da relação de pertencimento de seus membros, expressa sua identidade. A comida pode, então, ser tomada como linguagem, como texto cultural que fala do corpo, da família, do trabalho, de relações sociais, de visões de mundo.

Essas noções estão ancoradas na compreensão de que cultura pode ser entendida como totalidade de representações de uma coletividade, constituindo uma reunião de textos culturais ${ }^{7}$. Nessa perspectiva, cultivar, trabalhar, produzir, intercambiar, comer são ações humanas individuais e coletivas em que está presente um sistema de dádivas, de trocas materiais e simbólicas geradoras de reciprocidade, que se apresenta como fato social total ${ }^{8}$.

Desse modo, tendo presente o rural observado neste estudo, sugere-se que, nutrindo laços, a comida fala da família e da comunidade. Temperando tradições, a comida atualiza identidades, ao mesmo tempo em que sua hibridização evidencia a proximidade, material e simbólica, entre campo e cidade.

A respeito da realidade estudada, cabe comentar que, nas últimas décadas, as dinâmicas de trabalho e vida das famílias rurais do segmento que vem sendo nominado agricultura familiar modificaram-se profundamente, especialmente no Sul do País, em que o processo de modernização da agricultura desenvolveu-se com grande capilaridade. Entre os aspectos que evidenciam essas transformações, pode-se mencionar o emprego intensivo de insumos e maquinários na produção agropecuária e o aprofundamento da integração dessa produção ao setor agroindustrial, assim como a redução do tamanho das famílias e as facilidades de acesso a bens e valores urbanos decorrentes da melhoria do sistema de transportes e das tecnologias de comunicação. Compõem esse quadro, ainda, o envelhecimento da população rural, diretamente relacionado à crise dos padrões sucessórios anteriormente dominantes entre esses agricultores; bem como a crescente ocupação da força de trabalho de moradores de áreas rurais em atividades não-agrícolas. As 
dinâmicas e os contornos das transformações socioeconômicas da agricultura familiar nos últimos 40 anos, como decorrência do processo de modernização agrícola, são vastamente discutidos na literatura nacional e internacional. Uma abordagem recente sobre a temática pode ser encontrada em Schneider ${ }^{9}$. Para a região estudada, pode-se tomar por referência o trabalho de Beroldt et al. ${ }^{10}$.

À mobilidade, material e simbólica, entre campo e cidade, responsável por profundas transformações no trabalho e na vida das famílias rurais, poder-se-ia associar a degradação do saber-fazer alimentar e agrícola dessa gente, e das formas de sociabilidade das comunidades rurais.

Entretanto, a observação detalhada no âmbito da organização e dinâmica interna das famílias permite evidenciar que, entre esses agricultores, os cultivos e criações que empregam intensivamente as ditas tecnologias modernas coexistem, lado a lado, com técnicas tradicionais e uma expressiva produção de alimentos voltada ao autoconsumo dasfamílias, associada à garantia de sua segurança alimentar e, então, às suas estratégias de reprodução social. Do mesmo modo, pode-se notar que a troca de dias de trabalho com parentes e vizinhos, que lembra os antigos mutirões, especialmente em épocas de colheita, é prática comum entre esses agricultores. Ainda, destaca-se que também a circulação de sementes transgênicas (consideradas de última geração) se realiza a partir dos tradicionais mecanismos de reciprocidade.

Observa-se, também, que, se bem é verdade que muitos jovens rurais vêem na combinação entre emprego urbano e moradia rural uma etapa que antecede a migração definitiva, outros a afirmam como situação transitória, que Ihes permite ter acesso à renda autônoma, que não seria oportunizada pela unidade de produção familiar, a vigorar até a ocasião em que o pai transmitirá ao herdeiro a condição de responsável pela propriedade e pela família. Do mesmo modo, verifica-se a existência de inúmeras organizações comunitárias, religiosas ou não, cujas atividades perpassam a vida dessas famílias; e percebe-se, em diferentes momentos rituais, de festas a eleições, as hierarquias e classificações operadas localmente, ainda que vinculadas a territórios abrangentes.

O rural aqui focado é, assim, mais complexo do que algo que deixou de ser o que era para se transformar em seu contrário. E isso os dados da pesquisa permitem evidenciar.

\section{M É T O D O S}

Os dados e as evidências empíricas discutidos foram obtidos por meio de metodologia qualitativa de pesquisa, que associa à pesquisa social, como afirma $\mathrm{M}$ inayo ${ }^{11}$, sensibilidade para captar interfaces entre pensamento e base material, entre objeto e suas questões, entre ação do homem como sujeito histórico e as determinações que a condicionam. 0 método qualitativo, segundo a autora, também permite a incorporação de questões do significado e da intencionalidade como inerentes aos atos, às relações e às estruturas sociais, sendo estas últimas tomadas como construções humanas significativas.

Três estratégias de pesquisa foram utilizadas de modo complementar: observação participante, entrevistas estruturadas e não-estruturadas. A observação é definida por Ghiglione \& M atalon ${ }^{12}$ como um olhar sobre uma situação sem que essa seja modificada, atuando no plano da escolha da situação e não no que deve ser observado, e tendo por objetivo a coleta de dados sobre a mesma. A complementaridade de estratégias permitiu explorar melhor aquilo que Raynaut ${ }^{13}$ chama de campo das relações não-materiais, que compreende o conjunto de processos cuja articulação participa na organização, na reprodução e na transformação das representações mentais do mundo e dos modos de estruturação das relações sociais. Nesse campo, os fatos que o olhar científico busca identificar, descrever e compreender remetem a processos de produção, de circulação e de transmissão do sentido, tanto do ponto de vista da cultura coletiva (representações, valores e normas) quanto dos intercâmbios entre atores sociais. 
Nesse quadro, foram observadas as práticas de produção e de consumo de alimentos das famílias rurais, sua produção de alimentos voltada ao autoconsumo, os itens alimentícios habitualmente adquiridos, bem como as manifestações de sociabilidade em que tomam parte os alimentos. Ainda, as práticas atuais de produção e de consumo de alimentos, bem como as variedades vegetais e animais empregadas na alimentação, foram confrontadas com as de período precedente, anterior ao processo de erosão das biodiversidades e culturas locais, decorrente, em boa medida, da intensificação da produção agropecuária.

Do mesmo modo, foram observadas situações de festas comunitárias e outras práticas de sociabilidade entre vizinhos e parentes, bem como de cotidiano das famílias rurais estudadas. Informantes-chave, particularmente pessoas idosas, portadoras das histórias locais, foram entrevistados; assim como o foram jovens e mulheres, cujas perspectivas específicas procurou-se apreender.

Para as entrevistas estruturadas, foi utilizado um instrumento de coleta de dados constituído de um formulário com questões abertas e fechadas, que permitiram identificar as práticas de produção e consumo de alimentos de 48 famílias rurais, de três diferentes localidades ${ }^{(3)}$. Nas visitas às famílias, previamente agendadas, com duração aproximada de duas a três horas, quando o assunto versava sobre as práticas alimentares, a conversa foi registrada em fitas cassete, de modo a garantir que não se perdesse a riqueza das histórias contadas, que não poderia ser contida em um formulário. Essas visitas foram, ainda, oportunidade para tomar um chimarrão ou provar o vinho da casa; experimentar um queijo, um bolinho frito ou uma cuca(4); examinar o caderno de receitas; conhecer as ervas medicinais utilizadas pela família; ver a horta e as criações; comer frutas; observar a casa e a cozinha; escutar histórias. Essas experiências e observações enriqueceram os relatórios correspondentes a cada família, elaborados a partir das fitas gravadas, que, por sua vez, deram vida aos dados sistematizados ${ }^{(5)}$ a partir dos formulários.

Neste artigo, optou-se por privilegiar a análise de alguns aspectos relacionados à produção de alimentos voltada ao autoconsumo das famílias rurais observadas, bem como a apreensão, a partir da alimentação, de questões que remetem às suas identidades.

Cabe ainda mencionar que os procedimentos de pesquisa foram conduzidos em acordo com os princípios éticos contidos na Declaração de Helsinki (2000).

\section{RESULTA D OS E DISCUSSÃ O}

\section{Segurança alimentar: substantivo feminino}

Constituída por cerca de duas centenas de famílias rurais, predominantemente descendentes de imigrantes italianos, a localidade de Jacarezinho está situada a cerca de cinco quilômetros da sede do município de Encantado. Dada a proximidade do centro urbano entre seus moradores são muitos, particularmente jovens e mulheres, aqueles que se dedicam a ocupações não-agrícolas.

Jacarezinho conta com uma forte organização comunitária, que se articula, em boa medida, a partir da expressiva religiosidade de seus moradores. Junto à imponente capela católica, encontra-se o ginásio de esportes, que cumpre também o papel de salão comunitário e que, juntamente com a escola, o cemitério e alguns estabelecimentos comerciais, constituem o cenário em que se desenrola a vida social local. Ali, os

\footnotetext{
3 Fazenda Lohmann, Mato Queimado e Jacarezinho, pertencentes, respectivamente, aos municípios de Roca Sales, Vespasiano Corrêa e Encantado, todos situados na região do Vale do Taquari, Rio Grande do Sul. Na primeira localidade, as famílias são predominantemente descendentes de imigrantes de origem alemã, enquanto que nas duas outras o são de imigrantes italianos. 4 Espécie de pão doce com recheios e coberturas diversos, característico da culinária alemã.

${ }^{5}$ As informações foram sistematizadas em um banco de dados digitalizado em SPSS versão 12.0.
} 
moradores se reúnem em cultos, em reuniões do clube de mães ou do grupo de idosos, em ensaios do coral, em treinos do time de futebol, em mesas de carteado e rodas de chimarrão, em partidas de bocha, em almoços e bailes, em casamentos e funerais, nas festas e filós(6).

Agricultores e agricultoras de 18 famílias rurais da localidade responderam às questões do formulário. Integrantes de 6 dessas famílias foram selecionados para a realização de entrevistas em profundidade, especialmente mulheres, mas também seus maridos e alguns de seus filhos e filhas.

O tamanho das propriedades da maioria das famílias estudadas é inferior a 10 hectares. Dessa área, parte costuma ser destinada a cultivos e criações voltados à comercialização, parte é coberta por matas nativas ou capoeiras e uma pequena parcela, de cerca de 1 a 2 hectares, é dedicada à produção de alimentos para o consumo da família. Apesar de a área destinada à produção de alimentos voltada ao autoconsumo ser relativamente pequena, ela fornece alimentos em variedade e quantidade. A produção destinada ao autoconsumo abrange pequenas criações, hortas, pomares e pequenas lavouras. Entre os itens produzidos, pode-se mencionar diversos tipos de frutas, legumes e verduras; animais como galinhas, suínos, bovinos, caprinos e peixes; feijão e mandioca, leite e mel.

$\mathrm{Na}$ comunidade estudada, a análise da divisão do trabalho no interior das unidades familiares rurais, assim como nos trabalhos de Heredia et al. $^{14}$ e Brumer ${ }^{15}$, mostrou que são as mulheres, muitas vezes com a participação das filhas e de filhos mais jovens, as principais responsáveis pela horta e pelos pequenos cultivos e criações voltados ao autoconsumo, assim como pelos serviços domésticos, aí incluso o preparo das refeições. Também, do mesmo modo que indicado nos estudos citados, na atividade agrícola realizada em Jacarezinho, é diferenciada a valoração do trabalho de homens e mulheres, decorrência dos papéis sociais de gênero assumidos por uns e outras que, por sua vez, correspondem a relações hierárquicas estabelecidas no interior da família e na sociedade.

Pode-se sugerir que, a partir da valoração diferenciada do trabalho de agricultoras e agricultores, seja possível apreender a valoração diferenciada dos produtos desses trabalhos. É assim que os alimentos produzidos para o autoconsumo da família, predominantemente a partir do trabalho feminino, são considerados miudezas, termo utilizado para denominar os produtos que, oriundos das pequenas hortas, pomares e lavouras, não se destinam a atividades comerciais.

Entretanto, pode-se observar, em Jacarezinho, a disponibilidade de inúmeros tipos de alimentos, nas diferentes épocas do ano. Na maior parte das famílias estudadas, as refeições são preparadas, predominantemente, a partir de alimentos produzidos na propriedade ou obtidos em trocas com vizinhos. Ainda, as agricultoras entrevistadas são unânimes em afirmar que, na produção de alimentos voltada ao autoconsumo, não são, via de regra, utilizados insumos químicos, particularmente agrotóxicos ${ }^{16}$. Em suas palavras, é uma produção limpa.

Segundo Maluf \& Menezes $^{17}$, são três os pontos norteadores da segurança alimentar: a qualidade nutricional dos alimentos, inclusive a ausência de componentes químicos que possam lesar a saúde humana; os hábitos/cultura alimentar específicos de cada comunidade, de cada grupo social; e a sustentabilidade do sistema alimentar, ou seja, a contínua produção e presença de alimentos.

Desse modo, pode-se considerar que a produção de alimentos voltada ao autoconsumo tende, na localidade estudada, a garantir a segurança alimentar daquela gente, uma vez que,

\footnotetext{
6 Prática corrente em época anterior, nas comunidades rurais constituídas por agricultores descendentes de imigrantes italianos, os filós consistem em visitas entre vizinhos e parentes, ocasião para jogar cartas, conversar, rezar, cantar e, claro, ocasião em que comida e bebida são partilhadas.
} 
estando enraizada na história vivida pelas famílias e pela comunidade, tem por atributos a diversidade, a qualidade e a disponibilidade durante todo 0 ano. Ao menos assim parecem entender os moradores do lugar, que, a exemplo da agricultora cujo trecho de depoimento é reproduzido a seguir, consideram-se saudáveis por terem uma alimentação saudável: "Tive sete filhos em casa e, até hoje, nenhum deles ficou doente. Isso tudo porque sempre comeram bem e bastante. E não comiam porcarias, como esses salgadinhos e guaranás [...]".

Quando indagados sobre como era, antigamente, a produção voltada ao autoconsumo, os agricultores e agricultoras de Jacarezinho afirmam que havia uma maior fartura de alimentos, do mesmo modo que constatado por Brandão ${ }^{18}$, em um clássico estudo sobre o campesinato goiano, que evidencia que os agricultores faziam referência ao passado como época de fartura, quando a terra era mais produtiva e os alimentos abundantes e diversos.

Os entrevistados do Vale do Taquari relatam que, no passado, eram raros os itens comprados, sendo aí mencionados sal e café, e que muitos dos alimentos hoje adquiridos, como arroz, batata e cebola, eram então produzidos nas propriedades. Ainda, apontam que alguns dos alimentos que atualmente são obtidos no comércio teriam sido adotados em substituição a outros que, anteriormente, eram produzidos por eles: ao invés do açúcar branco, utilizavam o açúcar mascavo; a banha foi, em boa medida, substituída pelo óleo de soja, enquanto que a nata pelo creme vegetal industrializado.

A redução do tamanho das propriedades, devida a partilhas por herança ou vendas de terras; a concentração das atividades agrícolas em poucos cultivos e/ou criações destinados à comercialização; bem como a facilidade de acesso a mercados locais e o aumento da oferta de alimentos neles disponíveis, podem ser apontados como alguns dos fatores que concorreram para a redução da produção de alimentos voltada ao autoconsumo em Jacarezinho, do mesmo modo que o ocorrido no contexto observado por Brandão ${ }^{18}$.
No caso da região estudada, cabe ainda mencionar a relação de integração com agroindústrias como um elemento que contribuiu para que a produção própria de alimentos se reduzisse. Isso porque, sob alegação de razões de ordem sanitária, é vedado (pelas empresas integradoras) aos agriculto res que produzem aves ou suínos em sistemas integrados, criar outras raças de porcos ou aves em suas propriedades. Com isso, várias raças de animais desenvolvidas localmente (chamadas crioulas ou rústicas) foram perdidas, tendo sido seu consumo, via de regra, substituído pelo de animais geneticamente desenvolvidos para as criações de tipo industrial. Vale comentar que, quando destinados ao consumo da família, é costume separar alguns dos animais do lote a ser entregue às agroindústrias integradoras, mesmo que infringindo normas, alimentando-os com uma dieta rica em milho, pasto verde e sobras de alimentos durante alguns dias antes do abate. Essa dieta diferenciada teria por objetivo, segundo os informantes, "limpar" o animal de medicamentos e hormônios que compõem as rações industrializadas, bem como produzir carnes consideradas mais saborosas (ainda que nem tão saborosas como são consideradas as carnes dos animais de raças rústicas).

Segundo os agricultores e agricultoras entrevistados, também o desaparecimento dos moinhos coloniais da região contribuiu para a diminuição da produção de alimentos voltada ao autoconsumo, uma vez que, desde então, eles já não têm como transformar em farinhas os cereais que cultivam.

Ainda, no que se refere às mudanças nos modos de fazer a produção voltada ao autoconsumo, cabe destacar que, atualmente, a maior parte das agricultoras entrevistadas adquire, a cada ano, as sementes e mudas necessárias para cultivar suas hortas. Isso não ocorria há alguns anos, quando as sementes eram colhidas, postas a secar, embaladas e guardadas para o plantio seguinte, ou trocadas com vizinhas. Em geral, nas famílias em que mulheres de mais idade (em torno de 60 anos) permanecem trabalhando na produ- 
ção de alimentos destinada ao autoconsumo, a prática de circulação das sementes continua presente.

Talvez se possa, ainda, relacionar a redução da produção de alimentos voltada ao autoconsumo a algumas mudanças que, mais recentemente, vêm ocorrendo neste rural, particularmente no que se refere às decorrentes da crescente mobilidade entre campo e cidade. A predominância da evasão feminina do meio rural entre a população jovem foi já demonstrada em vários estudos, entre eles o de Brumer ${ }^{13}$, que associa esse processo à forma como se realiza a divisão sexual do trabalho no interior das famílias e à valoração desigual atribuída ao trabalho de homens e mulheres.

Em Jacarezinho, não são muitas as moças que vivem no meio rural e são ainda menos as que, ali permanecendo, dedicam-se ao trabalho agrícola. Pode-se sugerir que, migrando ou voltando-se para ocupações não-agrícolas, essas moças estejam buscando no trabalho urbano o reconhecimento que suas mães não alcançaram enquanto agricultoras.

Uma vez que, na realidade estudada, são costumeiramente as mulheres agricultoras as primeiras responsáveis pela produção de alimentos voltada ao autoconsumo, pode-se apontar que, se a não valorização de seu trabalho está entre os motivos de seu distanciamento do trabalho agrícola, estaria também entre os fatores a contribuir para a tendência de redução da produção de alimentos voltada ao autoconsumo. Por conseguinte, o não reconhecimento do trabalho das mulheres agricultoras concorreria para uma situação de insegurança alimentar.

\section{Circulação de alimentos: sociabilidade e segurança alimentar}

Nas localidades estudadas, as famílias costumam dar aos vizinhos e parentes os alimentos que "sobram". Os produtos que mais freqüentemente circulam entre as famílias rurais são: carne bovina; carne suína e seus derivados, como torresmo, morcela e salame; ovos; derivados de leite, como queijo, nata e manteiga. Há, ainda, doações de pães, biscoitos e massas; frutas e hortaliças.

A dádiva mostra seu lado paradoxal, já que a gratuidade demonstrada, a incondicionalidade, é capaz de selar a aliança que beneficiará a todos e, finalmente àquele que tomou a iniciativa do desinteresse ${ }^{19}$. 0 "dar" quando "sobra" vem a reforçar a tendência geral, apontada por Godbout ${ }^{20}$, de que os atores, no comportamento da dádiva, negam a obediência a regras, chegando a negar a importância da própria dádiva. Trechos de depoimentos de agricultores entrevistados evidenciam a percepção desta negação:

A gente até troca, só que dá, né? Daí, eles dão uma outra coisa, né?

Existe uma certa troca, tem algumas pessoas [...] meu irmão, que vem com uma cesta pra cá, com mandioca, com alguma coisa, e carrega fruta, vem com nozes, verdura [...] faz uma troca involuntária [...].

Pode-se identificar uma espécie de divisão complementar da produção, que evidenciaria a não fortuidade da existência de sobras, em que as trocas garantem que todos tenham uma maior variedade de tipos de alimentos disponíveis, embora não pareça haver qualquer espécie de cálculo ou de preocupação em medir quanto foi trocado, em estabelecer valores equivalentes de troca ou sincronização das trocas.

Aqui na vizinhança, é assim: se eu tenho uma coisa sobrando, eu dou, e se elas têm uma coisa sobrando, que eu não tenho, me dão. Daí vai assim, de mão em mão [...] muita gente troca: o vizinho mata [um boi ou um porco] e dá [pedaços de carne, partes do animal abatido], depois, nós matamos e damos.

Colhi um monte de pepino, então era um balde pra cá, uma bacia pra lá.

Para a grande maioria das famílias estudadas, independentemente da origem étnica ou da comunidade a que pertencem, as carnes bovina 
e suína aparecem como principais itens de troca. Essa constatação remete à consideração de dois diferentes aspectos, relacionados entre si.

0 primeiro deles se refere a um elemento apontado por Woortmann ${ }^{21}$ : no campo da reciprocidade, quanto maior o valor de uso, maior 0 valor de troca da coisa trocada. A carne é fonte de proteína nas dietas de muitas populações ao redor do mundo, ao mesmo tempo em que é um alimento cuja obtenção é relativamente mais difícil e cara. Nas localidades em estudo não é diferente. Os relatos sobre o passado referem-se, recorrentemente, à escassez de carne (particularmente bovina) na alimentação das famílias rurais:

Eu me criei de família bem pobre mesmo [...] meu pai tinha dificuldade até pra se alimentar, a gente não tinha o suficiente, pra ser bem sincero. Então, eu comento hoje, com meus filhos [...] final de ano, tem Natal, Ano Novo e tal... nós tá enjoado de carne de sal, churrasco [...] Aí, eu sempre digo pra eles, olha aí: graças a Deus! [...] porque nós, às vezes, esperava seis meses pra poder comer um churrasco, quando era convidado para um casamento, uma coisa assim, né? Pra comer um churrasco!

Se, por um lado, a carne fora item de difícil acesso, por outro, escuta-se hoje que "aqui, ninguém sabe fazer comida sem um pedaço de carne" . Tradições, significados e hábitos misturamse, conferindo a esse alimento uma grandeza de valor, que estimula a continuidade da troca como expressão da reciprocidade: o dom corresponde à valorização cultural atribuída a um dado alimento pelo grupo social. Mesmo quando a disseminação de luz elétrica, geladeiras e congeladores já esvaziaram a funcionalidade da troca que, em época passada, era dada pela precariedade dos métodos de conservação.

O segundo aspecto a destacar é que a dádiva, segundo Godbout ${ }^{20}$, não contida nos determinismos, é acompanhada por uma certa sensação de euforia e pela impressão de participação em algo que ultrapassa a necessidade de ordem material. Assim é que a raridade, nos dias de hoje, dos mutirões de trabalho, lembrada pelos mais velhos com pesar, é, de certa forma, compensada pela mobilização coletiva que, em clima festivo, é observada quando vizinhos e parentes se reúnem para 'carnear'(7) um animal. Tal costume extrapola a simples necessidade e reafirma a dádiva, vivida, neste momento, na ajuda mútua.

Entretanto, são perceptíveis mudanças no sistema de trocas de alimentos, decorrentes, por exemplo, da diminuição da produção para o autoconsumo, justificada de diferentes maneiras pelos agricultores e agricultoras entrevistados:

Os velhos não estão mais, esses novos não se interessam mais, a colônia não tem mais ninguém [...] ficam do is ou três, os outros trabalham nas firmas.

Não vale nem a pena tu plantar, o arroz é uma coisa barata, né? Tu tem que capinar, tu tem que plantar, tem que colher, não vale nem a pena... [justificando 0 abandono do cultivo do arroz para autoconsumo].

A utilização da (pouca) mão-de-obra disponível para o trabalho agrícola na unidade familiar acaba por privilegiar os produtos destinados ao mercado. Assim, a redução do tamanho das famílias, o envelhecimento da população rural e a crescente dedicação de jovens a ocupações nãoagrícolas vêm provocando, no que se refere à circulação de alimentos entre as famílias rurais, 0 surgimento de outros tipos de vínculos, mercantis inclusive.

Nas localidades estudadas, os alimentos mais freqüentemente adquiridos de vizinhos são queijo e carne, seguidos pelo feijão. Uma grande variedade de outros produtos provêm, principalmente, de supermercados, situados em centros urbanos próximos. Também frutas e hortaliças são

$\overline{7 \text { Termo utilizado entre }}$ s agricultores observados para designar o abate de animais. 
compradas, destacando-se cebola, tomate, banana e mamão, enquanto que batata, arroz e trigo são os alimentos cujas áreas destinadas à produção para autoconsumo mais diminuíram nos últimos anos.

No caso da produção de leite e queijo, por exemplo, vem se tornando comum que algumas mulheres os produzam em quantidade suficiente para comercializar com vizinhas e parentes. Como discutido anteriormente, são as mulheres agricultoras que, predominantemente, respondem pelos pequenos cultivos e criações destinados ao abastecimento da família. Do mesmo modo, elas são também protagonistas nas redes de vizinhança e parentesco em que circulam os alimentos. A fala de uma das agricultoras entrevistadas pode ser tomada como ilustração:

A última vaquinha, era uma vaquinha pequena que nós tínhamos, uma Jérsei, mas dava bastantinho leite [...] Imagina, com duas escolas [ela é professora, o marido se dedica à agricultura], aí eu acabei vendendo [a vaca] [...]. O leite, eu compro em caixinha, vem desnatado [...] o queijo, eu compro da minha cunhada.

As famílias em que predominam pessoas idosas são, com freqüência, as que mais adquirem alimentos de vizinhos. M uitas " compradoras" são agricultoras que, agora recebendo aposentadoria, preferem comprar de vizinhas (e não no supermercado) os alimentos que já não produzem.

A relação mercantil é, comumente, colocada em oposição à relação de reciprocidade. Entretanto, Sabourin ${ }^{22}$ aponta a possibilidade de existência de formas de mercado que associem princípios de reciprocidade, propondo que algumas práticas mercantis podem estar fundadas em princípios diferentes do utilitarista da redistribuição pelo intercâmbio livre. Como ensina $\mathrm{Mauss}^{8}$, ao relacionar coisas e signos, as coisas vendidas possuem ainda uma alma.

No caso específico dos alimentos comercializados entre as famílias rurais das localidades estudadas, há valores não negligenciáveis relacionados: a confiança e a tradição. Há, ainda, um sistema de valores partilhados, que age na valoração da qualidade dos alimentos, como se percebe na fala de um dos agricultores:

O que importa não é se o leite está no tarro ou no resfriador, o que importa é se o animal está sadio, o capricho na ordenha. Antigamente, a mãe tirava o leite e a gente ia com a canequinha lá e a gente botava o leite e tomava assim, natural, como saía.

É importante ter presente que tais transformações, em que cada vez mais as trocas são mediadas pela moeda, não necessariamente contribuem para o fim de um modo de vida ou para o desaparecimento da dádiva. Godbout ${ }^{20}$ indica que os laços sociais apenas vão se desfazer pela ausência da dívida (característica do mercado liberal). No caso estudado, porém, há uma troca equivalente, um pagamento, mas a dívida permanece. Isso porque há outros compromissos, firmados entre as partes, que não desaparecem. Não se trata, então, de uma troca completa, que ocorreria em sentido contrário à dádiva.

Tem-se, também, que o comércio entre vizinhos representa, para essas famílias, divisão do trabalho com diminuição de sua penosidade. Em seus depoimentos, freqüentemente os entrevistados sugerem que o excesso de atividades ininterruptas, ao longo do ano, é fator que leva ao desinteresse pela agricultura e à fuga do rural. Destaca-se que tal ponto de vista é especialmente apresentado por mulheres agricultoras, comumente submetidas a jornadas de trabalho particularmente extenuantes.

Ainda, o comércio entre vizinhos amplia possibilidades de ingresso de renda e, localmente, a circulação de riqueza. De pontos de vista distintos, observa-se, nos depoimentos abaixo, a importância atribuída ao comércio do excedente produzido para o autoconsumo:

Não parece, né? Má, tem vezes, que nós ganhamos mais com esses produtos do que com o milho [principal atividade agrícola destinada à comercialização]. 
Esse ano, com a seca, o milho não deu nada. Ainda que nós sempre vendemos umas peças de queijo, uns ovos de galinha, de vez em quando, prá se comprar o que se precisa. Se não fosse por isso, nós morria de fome.

Sempre que tu precisa de alguma coisa, tu procura na comunidade. São alimentos mais saudáveis.

Evidencia-se, assim, que essas trocas mercantis são impregnadas pelo simbólico, pela confiança e mesmo pelo prestígio, que atualizam um modo de vida, em um mundo em transformação. A campesinidade é, assim, aqui apreendida como dinâmica, e não a partir de visão substantivada, em que estaria associada a um modo de vida estático, característico de épocas passadas ou de situações rurais integradas de forma tênue ao mercado.

Entretanto, não se deve perder de vista que a crescente mercantilização do consumo pode estar associada à insegurança alimentar do grupo doméstico ${ }^{23}$. Tal insegurança, de fato, é um risco iminente na ausência do rico sistema de dádivas, cultivado no interior dos mecanismos de reciprocidade gerados e geradores de vínculos sociais. No que se refere a esses vínculos, pode-se considerar que as obrigações individual e coletiva estão de tal forma imbricadas, zelando pela construção permanente da identidade e da alteridade, que, ao contrário de promover a atomização do individualismo, promovem autonomia e compromisso.

\section{Segurança alimentar: comida e identidade}

A expressão da dádiva compreende, como visto, a doação em si e os significados em que está envolta. E quando se fala de alimentos e agricultura, é especialmente dádiva o trabalho, 0 esforço e o saber-fazer, de quem plantou, colheu ou preparou a comida.

Tal expressão, que se manifesta com freqüência na família, pode também ser observada no âmbito da comunidade, em que fazer/doar um alimento para uma festa ou reunião, transcende o valor em si. São faces do sistema contratual da dádiva, das prestações e contraprestações que Mauss $^{8}$ associa à honra e ao prestígio. Pois a obrigação de dar é que garante a honra e o prestígio; a obrigação de receber mantém e reproduz a hierarquia, já que a aceitação de uma dádiva cria comprometimento; a obrigação de retribuir garante a permanência do vínculo, o pertencimento: aí se reiteram os laços, constitui-se a aliança.

M as não apenas a circulação de alimentos é perpassada por aspectos simbólicos. Como já dito, também o são as próprias escolhas alimentares. E, nesse sentido, a comida de festa pode ser considerada particularmente emblemática, especialmente quando observadas as festas que marcam a vida social das comunidades rurais estudadas. Em sua realização, são atualizadas, além das relações de sociabilidade, também as expressões de identidade dos grupos sociais. E isso se dá, em boa medida, a partir da comida.

Assim é que, enquanto que no Filó do Jacarezinho a polenta brustolada ${ }^{(8)}$ é presença obrigatória, bem como os queijos, salames e vinhos, trazidos pelas famílias para partilhar com as demais, no baile de Kerb(9) de Fazenda Lohmann são servidas lingüiças cozidas, acompanhadas por cucas. Enquanto que as cucas são preparadas por um grupo de mulheres, em mutirão, as lingüiças são produzidas por um grupo de homens da comunidade, que são os responsáveis pela seleção dos animais a serem abatidos, pelo abate, pela preparação das carnes e sua transformação em lingüiças. Eles são detentores dos segredos referentes às misturas de carnes e aos temperos empregados, portadores, assim, do saber-fazer

\footnotetext{
8 Assada na chapa.

${ }^{9}$ Festa realizada anualmente, por ocasião do aniversário da igreja (para os evangélicos) ou do dia do padroeiro da paróquia (para os católicos) nas comunidades rurais constituídas por agricultores descendentes de imigrantes de origem al emã.
} 
reconhecido no resultado dos embutidos considerados apropriados, e que, atualmente, são produzidos especialmente para a ocasião festiva e, desse modo, culturalmente valorizados.

É interessante notar que, à mesa cotidiana dos agricultores estão presentes inúmeros produtos industrializados ou adquiridos no mercado e que, aos domingos e nas comemorações familiares, 0 churrasco (prato marcador da identidade gaúcha) substituiu, em boa medida, os pratos tradicionais das culinárias italiana e alemã, característicos das localidades estudadas. Entretanto, esses últimos permanecem sendo os alimentos servidos em suas festas comunitárias.

Ao argumentar que produzem uma grande variedade de alimentos, classificados por eles como de qualidade superior à daqueles disponíveis no mercado, os agricultores e agricultoras entrevistados consideram que sua segurança alimentar não está ameaçada, ao mesmo tempo em que avaliam como saudável sua alimentação. "Se tu quer comer coisa boa, hoje tu tem que plantar". "Nas coisas que vai pra casa, a gente não bota veneno. Eu tenho medo do que eu compro, não do que eu colho".

Assim, ainda que amplamente consumidos, os alimentos industrializados/adquiridos no mercado são, entre essas famílias rurais, comumente objeto de desconfiança, na medida em que argumentam que em sua composição estão presentes aditivos químicos e/ou agrotóxicos, assim como é desconhecido o processo de sua produção. Já, o que é produzido "em casa" é associado à "comida de antigamente" e, por conseguinte, recebe 0 adjetivo "natural", como no trecho do depoimento de uma agricultora de Fazenda Lohmann, reproduzido abaixo:

A alimentação era mais natural [...] Acho que mudou a alimentação porque tudo era mais feito em casa, e também praticamente o sustento só da roça [...] Antigamente, também a comida era bastante gordurosa [...] porque eles trabalhavam mais assim na roça, então precisava de alimentos que sustentassem.
Por outro lado, a comida de antigamente, considerada adequada às exigências do trabalho físico intenso então realizado, é, a exemplo do trecho de depoimento reproduzido anteriormente, apontada como sendo mais gordurosa, em clara referência ao discurso medicalizado sobre a alimentação, que, amplamente difundido pelos meios de comunicação de massa, pode, tal como sugerido por Romanelli24, ser considerado como prevalente na sociedade. 0 trecho de entrevista realizada junto a um agricultor de M ato Queimado, reproduzido abaixo, reitera tal concepção.

A gente costumava fazer o seguinte, no tempo que nós tava em casa. Nós era uma turma de 10, 12 em roda da mesa, assim. De manhã cedo, nós fazia o café em cima do fogão. A falecida mãe, então, pegava uma bacia pequena assim, uma frigideira, assim, botava lá um meio quilo de banha dentro, cortava mais [...] toicinho de porco, mais um pedacinho de salame, assim [...] dentro da frigideira, frigia aquilo tudo lá, depois ainda botava uns três, quatro ovos, por cima. E se sentava tudo em roda daquele fogão lá, e aí volteava aquele pão dentro daquela banha, e aqui ó [faz sinal com a mão, em direção à boca]. Depois, por cima, mais um canequinho de água, e pronto. 0 café era esse. Trabalhava até meio-dia, que nem burro! Hoje, se eu faço isso aí, uma semana, 15 dias, fico no médico.

Mas, ao mesmo tempo em que é adjetivada como mais gordurosa, a " comida da colônia" é classificada pelos agricultores das localidades estudadas - do mesmo modo que o identificado em estudos que, a exemplo de Brandão ${ }^{18}$, Woortmann ${ }^{25}$ e Woortmann \& Woortmann ${ }^{26}$, dedicaram-se a apreender os significados da alimentação entre grupos camponeses - como mais "forte". Veja-se o que diz um agricultor de Jacarezinho entrevistado:

Parece que agora é uma comida mais leve quase tudo, né? Se ela não vem da colônia, porque aquela que vem da 
colônia é um pouco mais [...] não sei, é um pouco diferente, não vou dizer que ela é mais forte nem mais fraca, eu acho que é mais forte [...] é natural.

A comida da colônia é, desse modo, valorada como 'natural' e 'forte', em contraposição aos alimentos industrializados e vindos de fora, que compõem uma culinária mais 'leve' e 'fraca' e que, não sendo 'natural' (por conter produtos químicos), oferece riscos à saúde. Assim, a alimentação gordurosa (forte), ainda que, nos dias de hoje, proscrita pelo discurso medicalizado e apontada como inadequada ao ritmo atual de trabalho daqueles que vivem no meio rural (menos intenso do que em época anterior) é, por 'natural', considerada mais saudável.

Nas entrevistas, os agricultores e agricultoras declararam, recorrentemente, que sua principal contribuição à sociedade está relacionada à produção de alimentos. É assim que reconhecem seu lugar no mundo: o lugar daqueles que produzem a comida. Isso em uma sociedade em que 0 rural é associado à idéia de atraso; em que os modos de falar, vestir e agir da gente da terra são, no contato com os citadinos, historicamente depreciados; em que aqueles que vivem e trabalham no campo são classificados como cidadãos de segunda categoria.

O tema da depreciação simbólica como constitutiva do campesinato foi objeto de inúmeros estudos. A título de exemplo, cale mencionar o trabalho de M oura27 e, especialmente, os estudos realizados por Bourdieu em sua região natal, 0 Béarn ${ }^{28}$. Ainda, como ilustração, vale lembrar que, apenas recentemente (a partir da Constituição de 1988), os trabalhadores do campo brasileiros passaram a ter direito à aposentadoria equivalente àquela recebida pelos trabalhadores urbanos. A té então, o valor da aposentadoria rural era de ape- nas meio salário-mínimo mensal, a metade do que recebiam seus colegas da cidade - o que os levava a afirmar que a sociedade e a legislação brasileiras consideravam o trabalhador rural como "meio-homem".

Diante desse tratamento que lhes é dispensado, os colonos ${ }^{(10)}$ afirmam, então, a dimensão positiva de sua identidade, associada à comida: têm orgulho de, a partir de seu trabalho, serem aqueles que a produzem.

Desse modo, em um contexto em que as dinâmicas de vida e trabalho dessas famílias rurais vêm passando por intensas mudanças, a força dessa gente, assim como é 'forte' sua comida; é afirmada a partir de sua associação à segurança alimentar.

\section{COLABORADORES}

R. MENASCHE idealizou e coordenou o projeto, além de participar de todas as fases da pesquisa e da redação deste artigo. F.C. MARQUES colaborou na elaboração do projeto, na realização das entrevistas, na coleta e na sistematização de dados, bem como na redação do presente artigo. C. ZANETTI participou de todas as fases da pesquisa, na qualidade de bolsista de iniciação científica, e colaborou na redação deste artigo.

\section{REFERÊ N CIAS}

1. Menasche R, organizadora. A agricultura familiar à mesa: saberes e práticas da alimentação no Vale do Taquari. Porto Alegre: UFRGS; 2007.

2. Graziano da Silva J, Del Grossi ME. O novo rural brasileiro: uma atualização para 1992-98 [acesso em 2006 dez 16]. Disponível em: <http://www.eco. unicamp.br/nea/rurbano/rurbanw.html>.

3. Carneiro MJ, Maluf RS, organizadores. Para além da produção: multifuncionalidade e agricultura familiar. Rio de Janeiro: Mauad; 2003.

\footnotetext{
100 termo colono, empregado, especialmente no Sul do País, para designar os agricultores descendentes de imigrantes europeus, tem sua origem na administração colonial: "para o Estado, eram colonos todos aqueles que recebiam um lote de terras em áreas destinadas à colonização", explica Seyferth ${ }^{29}$. A apropriação da categoria administrativa pelos agricultores de origem européia como definidora de sua identidade se daria, explica a autora, com a exclusão daqueles chamados caboclos ou brasileiros. Assim, "colono é a categoria designativa do camponês [...] e sua marca registrada é a posse de uma colônia [...] a pequena propriedade familiar" (p.80).
} 
4. Poulain JP, Proença RPC. O espaço social alimentar: um instrumento para o estudo dos modelos alimentares. Rev Nutr. 2003; 16(3):245-56.

5. Fischler C. Présentation. Communications. 1979; 31:1-3.

6. Da Matta R. Sobre o simbolismo da comida no Brasil. O Correio da Unesco. 1987; 15(7):22-3.

7. Woortmann K. A comida, a família e a construção do gênero feminino. Dados. 1986; 29 (1):103-130.

8. Mauss M. Ensaio sobre a dádiva. Lisboa: Edições 70; 1988.

9. Schneider S, organizador. A diversidade da agricultura familiar. Porto Alegre: UFRGS; 2006.

10. Beroldt L, Grisel PN, Schmitz JAK. Evolução e diferenciação da agricultura no Vale do Taquari: um estudo comparado de dois sistemas agrários. In: Menasche $\mathrm{R}$, organizadora. A agricultura familiar à mesa: saberes e práticas da alimentação no Vale do Taquari. Porto Alegre: UFRGS; 2007.

11. Minayo MCS. O desafio do conhecimento. Pesquisa qualitativa em saúde. São Paulo: Hucitec; 1992.

12. Ghiglione R, Matalon B. O inquérito: teoria e prática. Oeiras: Celta; 1997.

13. Raynaut C. Meio ambiente e desenvolvimento: construindo um novo campo do saber a partir da perspectiva interdisciplinar. Desenv Meio Ambiente. 2004; 10:21-32.

14. Heredia B, Garcia M F, Garcia Junior A. O lugar da mulher em unidades domésticas camponesas. In: Aguiar N, coordenadora. Mulheres na força de trabalho na América Latina. Petrópolis: Vozes; 1984.

15. Brumer A. Gênero e agricultura: a situação da mulher na agricultura do Rio Grande do Sul. Rev Estud Feministas. 2004; 12(1):205-27.

16. Menasche R. Capinar: verbo conjugado no feminino? Notas de pesquisa sobre gênero $e$ percepções de risco na agricultura familiar. Cuad Desarrollo Rural. 2004; 53:25-36.
17. Maluf RS, Menezes F. Caderno 'segurança alimentar'. [acesso 2006 dez 19]. Disponível em: $<$ <ttp://www.forumsocialmundial.org.br/>.

18. Brandão CR. Plantar, colher, comer: um estudo sobre o campesinato goiano. Rio de Janeiro: Graal; 1981.

19. Caillé A. Nem holismo nem individualismo metodológicos: Marcel Mauss e o paradigma da dádiva. Rev Bras Ciênc Soc. 1998; 13(38):5-37.

20. Godbout JT. Introdução à dádiva. Rev Bras Ciênc Soc. 1998; 13(38):39-51.

21. Woortmann K. Com parente não se neguceia: 0 campesinato como ordem moral. An Antropol. 1990; 87:11-73.

22. Sabourin E. Dádiva e reciprocidade nas sociedades rurais contemporâneas. Tomo. 2004; 7:75-103.

23. Gazolla M. Agricultura familiar, segurança alimentar e políticas públicas: uma análise a partir da produção para autoconsumo no território do Alto Uruguai/RS [dissertação]. Porto Alegre: Universidade Federal do Rio Grande do Sul; 2004.

24. Romanelli G. O significado da alimentação na família: uma visão antropológica. Medicina. 2006; 39(3):333-9.

25. Woortmann K. Hábitos e ideologias alimentares em grupos sociais de baixa renda: relatório final. Série Antropologia. 1978 [acesso 2006 out 17]; 20. Disponível em: <http://www.unb.br/ics/dan/ serie_antro.htm>.

26. Woortmann EF, Woortmann K. O trabalho da terra: a lógica e a simbólica da lavoura camponesa. Brasília: UnB; 1997.

27. Moura M M. Camponeses. São Paulo: Ática; 1986.

28. Bourdieu P. Célibat et condition paysanne. Études Rurales. 1962; 5(6):32-136.

29. Seyferth G. As contradições da liberdade: análise de representações sobre a identidade camponesa. Rev Bras Ciênc Soc. 1992; 7(18):78-95.

Recebido em: 1/3/2007

Versão final reapresentado em: 4/4/2008

Aprovado em: 9/5/2008 